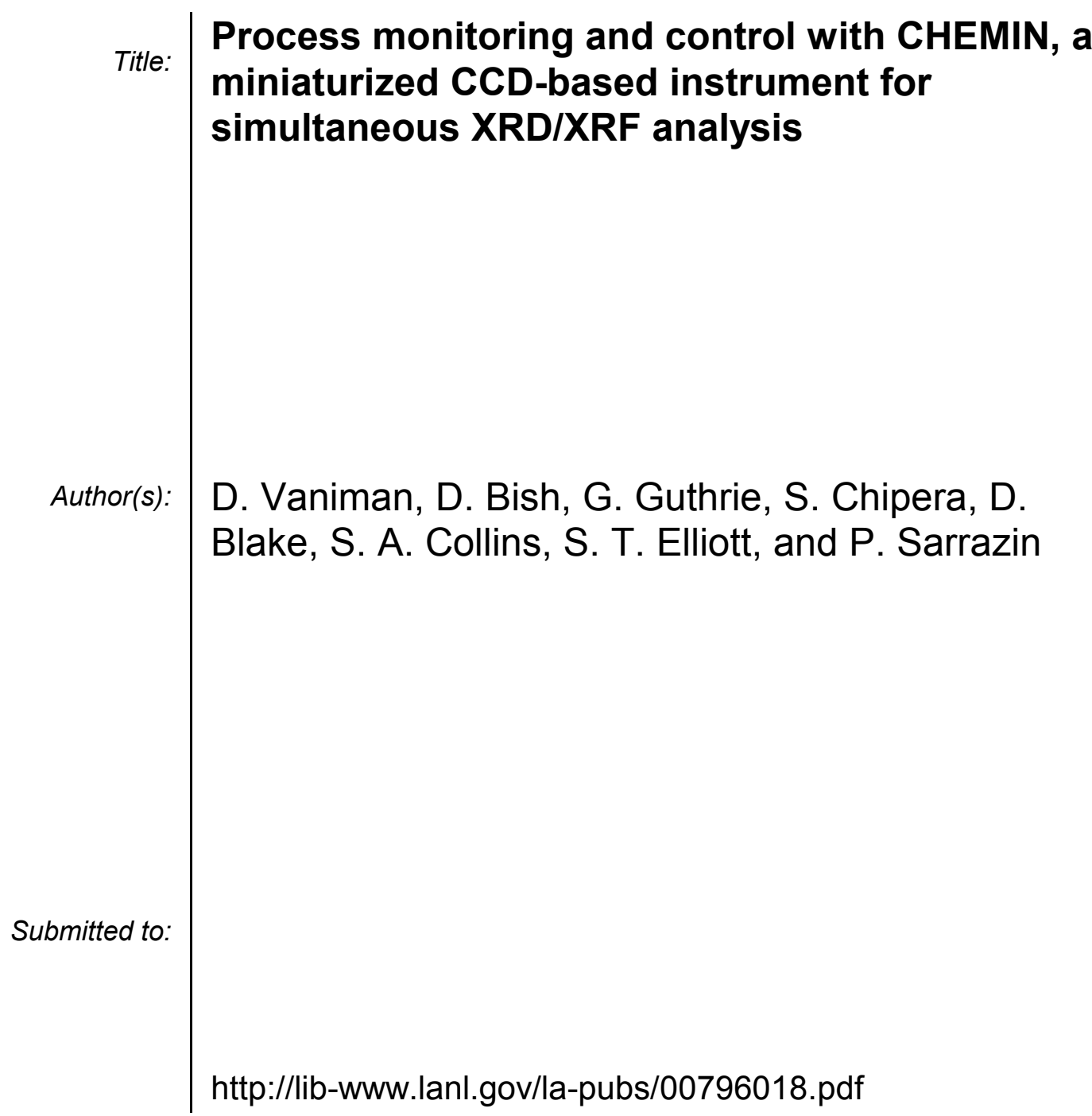

Los Alamos National Laboratory, an affirmative action/equal opportunity employer, is operated by the University of California for the U.S. Department of Energy under contract W-7405-ENG-36. By acceptance of this article, the publisher recognizes that the U.S. Government retains a nonexclusive, royaltyfree license to publish or reproduce the published form of this contribution, or to allow others to do so, for U.S. Government purposes. Los Alamos National Laboratory requests that the publisher identify this article as work performed under the auspices of the U.S. Department of Energy. Los Alamos National Laboratory strongly supports academic freedom and a researcher's right to publish; as an institution, however, the Laboratory does not endorse the viewpoint of a publication or guarantee its technical correctness. 


\title{
Process monitoring and control with CHEMIN, a miniaturized CCD-based instrument for simultaneous XRD/XRF analysis
}

\author{
D. Vaniman ${ }^{*}$, D. Bish ${ }^{\mathrm{a}}$, G. Guthrie ${ }^{\mathrm{a}}$, S. Chipera ${ }^{\mathrm{a}}$, D. Blake ${ }^{\mathrm{b}}$, S. A. Collins ${ }^{\mathrm{c}}$, S. T. Elliott ${ }^{\mathrm{c}}$, \\ and P. Sarrazin ${ }^{\mathrm{d}}$ \\ ${ }^{\mathrm{a}}$ Geology and Geochemistry, MS D462, Los Alamos National Laboratory, Los Alamos, NM 87545 \\ ${ }^{\mathrm{b}}$ NASA Ames Research Center, Mail Stop 239-4, Moffett Field, CA 94035 \\ ${ }^{c}$ Detector Advanced Development, 300-315, Jet Propulsion Laboratory, 4800 Oak Grove Drive, \\ Pasadena, CA 91109 \\ ${ }^{\mathrm{d}}$ Etablissement National d'Enseignement Supérieur Agronomique de Dijon (ENESAD), Laboratoire en \\ Génie des Agroéquipements et des Procédés, 21, bd O. de Serres 21800, Quetigny, France
}

\begin{abstract}
There is a large variety of mining and manufacturing operations where process monitoring and control can benefit from onsite analysis of both chemical and mineralogic constituents. CHEMIN is a CCD-based instrument capable of both X-ray fluorescence (XRF; chemical) and X-ray diffraction (XRD; mineralogic) analysis. Monitoring and control with an instrument like CHEMIN can be applied to feedstocks, intermediate materials, and final products to optimize production. Examples include control of cement feedstock, of ore for smelting, and of minerals that pose inhalation hazards in the workplace. The combined XRD/XRF capability of CHEMIN can be used wherever a desired commodity is associated with unwanted constituents that may be similar in chemistry or structure but not both (e.g., Ca in both gypsum and feldspar, where only the gypsum is desired to make wallboard). In the mining industry, CHEMIN can determine mineral abundances on the spot and enable more economical mining by providing the means to quickly and frequently assay the material being mined, at minimal cost. In manufacturing, CHEMIN could be used to spot-check the chemical composition and crystalline makeup of a product at any stage of production. Analysis by CHEMIN can be used as feedback in manufacturing processes where rates of heating, process temperature, mixture of feedstocks, and other variables must be adjusted in real time to correct structure and/or chemistry of the product (e.g., prevention of periclase and alkali sulfate coproduction in cement manufacture).
\end{abstract}

Keywords: X-ray diffraction, X-ray fluorescence, $\mathrm{CCD}$, mineralogy, process control

\section{INTRODUCTION: PRINCIPLES OF CHEMIN OPERATION}

CHEMIN is a CCD-based simultaneous $\mathrm{X}$-ray diffraction/X-ray fluorescence (XRD/XRF) instrument designed to simultaneously obtain elemental composition and mineralogy. No other instrument has a comparable capability of simultaneously collecting both X-ray diffraction and X-ray fluorescence data from single samples. In addition, CHEMIN can handle much smaller samples than conventional separate laboratory XRD and XRF systems. This is important where a small sample has been synthesized or collected and knowledge of composition and structure is needed (e.g., rare new minerals that are difficult to find; synthesis of special materials that can only be made in small amounts or are hazardous in large amounts).

XRD and XRF data can be obtained simultaneously on an instrument fitted with either a back-illuminated CCD, or a unique front-illuminated thin-gate CCD, and operated in single-photon counting mode (Fig. 1). Energy discrimination is used to distinguish between diffracted characteristic photons and fluorescence photons. In XRD applications, a CCD is much cheaper and far more energy sensitive than existing image plates. The quality of the XRD data is enhanced by full Debyering integration, and the resulting XRD data are sufficient for determination of mineral abundances and structures using Rietveld refinement. Even compared with dedicated X-ray diffraction systems that do not perform XRF, CHEMIN has important advantages in XRD capability. When diffracted photons are recorded by a detector, a two-dimensional diffraction

*Correspondence: Email: vaniman@lanl.gov; WWW: http://chemin.lanl.gov; Telephone: 505667 1863; FAX: 5056653285 


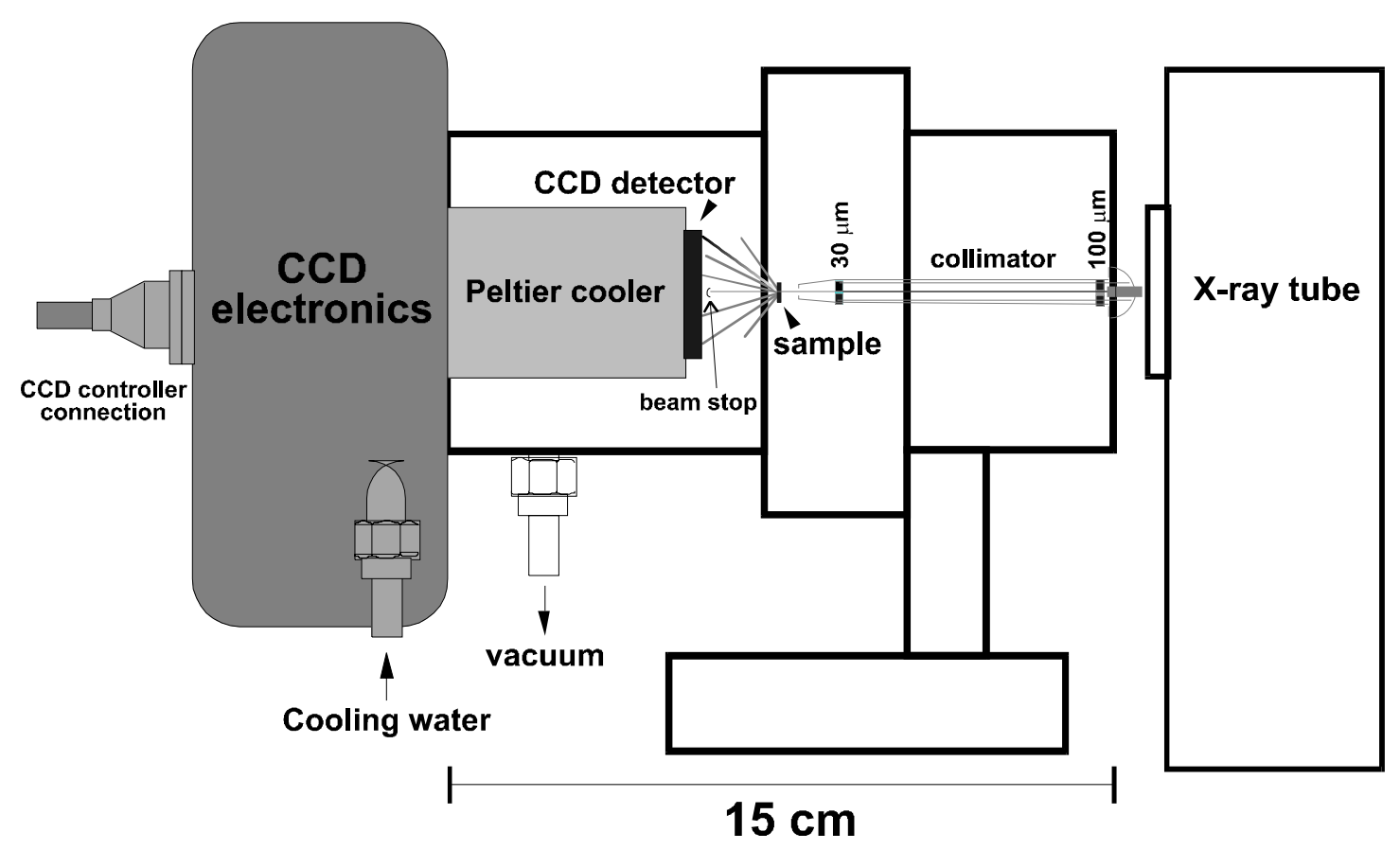

Fig. 1: Components of the prototype CHEMIN XRD/XRF instrument. The CCD collects diffracted primary $\mathrm{Cu}$ radiation from the $\mathrm{X}$-ray tube as symmetric rings on the $\mathrm{CCD}$; secondary radiation from the sample, identified by energies $\neq \mathrm{Cu} \mathrm{K} \alpha$, impinges on the $\mathrm{CCD}$ without pattern and is summed and binned by energy.

pattern emerges in the form of concentric rings (Fig. 2a). Conventional X-ray cameras and diffractometers scan only a narrow band across the diffraction pattern, quantified from film along the length of the band with an optical densitometer or from the center to the edge of the pattern with a diffractometer (Fig. 2b). If the diffraction rings are not complete-for example, because a sample is poorly powdered - the scan may miss essential data. As a result, samples for conventional diffractometers must be finely powdered to ensure that the crystals are numerous and randomly oriented. With CHEMIN the entire diffraction ring is captured by summing all the diffraction spots in each Debye ring; thus samples for CHEMIN require less intensive preparation. If a sample is poorly prepared - if the crystals are not randomly oriented or the sample is poorly powdered - it is still possible to obtain high-quality data. CHEMIN also provides accurate data for samples of less than $1 \mathrm{mg}$.

For XRF analysis, back-thinned and back-illuminated CCDs are typically used. An advanced front-illuminated thin-gate $\mathrm{CCD}$, although not yet commercially available, can obtain XRF data for elements with $4<Z<92$; light-element measurement is exceptionally good at low energy (FWHM of $38 \mathrm{eV}$ at $277 \mathrm{eV}$ ) with this CCD, developed at the Jet Propulsion Laboratory (JPL). ${ }^{1}$ The front-illuminated thin-gate $\mathrm{CCD}$ has a quantum efficiency that peaks at about $1 \mathrm{KeV}$, with an optimum range from about 250 to $8000 \mathrm{eV}$. Energy resolution is better than $100 \mathrm{eV}$ (FWHM) over much of this range. Although thinning and backside illumination can improve the low-energy sensitivity of a CCD (Fig. 3), these approaches also entail significant drawbacks, including charge splitting between adjacent pixels, lower charge-transfer efficiency, greater noise, and poorer spectral resolution (FWHM of 100-120 eV, nearly independent of energy). ${ }^{2}$ Because of these effects, the light-element measurement with a back-thinned and back-illuminated CCD is poorer than with the front-illuminated thin-gate design. Nevertheless, a common commercial back-illuminated CCD is still capable of analyzing elements in the range of $13<Z<92$.

Because CHEMIN produces both diffraction and fluorescence data, simultaneous linear equations can be used to derive the most accurate mineral and chemical composition. The combination of XRD and XRF capability gives CHEMIN exceptional potential in many industrial applications where process monitoring and control are important. CHEMIN analyses can be used to monitor products or intermediate forms in order to optimize feedstocks and system parameters. For example, in Portland cement production desired mineral sources of $\mathrm{Ca}, \mathrm{Si}, \mathrm{Al}$ and $\mathrm{Fe}$ and undesired mineral sources of $\mathrm{Mg}, \mathrm{Na}$, and $\mathrm{K}$ are important feedstock parameters. Real-time CHEMIN data on feedstock and product mineralogy can be used to adjust kiln operations and optimize cement phase abundances by direct analysis (in contrast to the Bogue method, which calculates these phases indirectly) and to minimize unwanted phases such as periclase and alkali sulfates (see section 4, below). 

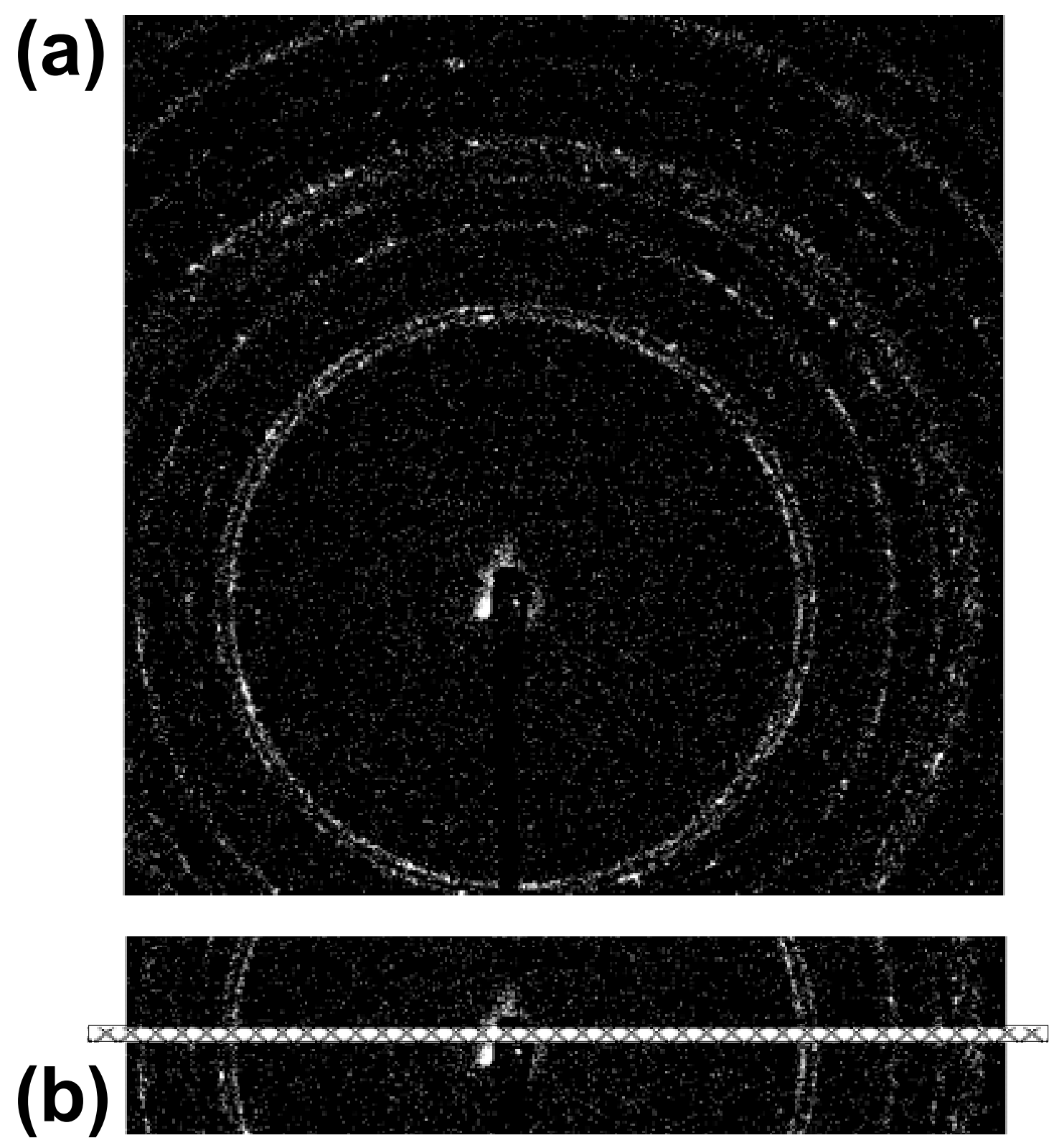

Fig. 2: $\mathrm{CCD}$ image of diffracted $\mathrm{Cu} \mathrm{K} \alpha$ radiation from a poorly powdered sample of aragonite (a). Note the "spotty" distribution of diffracted X-rays within the Debye rings. Despite the poor continuity of the Debye rings, the circumferential integration of each entire ring by the CHEMIN system results in $100 \%$ data use, effective averaging of irregular intensity, and a very well-defined pattern of intensity versus $2 \theta$. Panel (b) shows the area more typically sampled in Debye-Scherrer diffraction cameras, limited to a narrow strip. The cross-hatched line within this strip shows the analytical area typically sampled by an optical densitometer (along the entire line) or by a conventional laboratory diffractometer (from center to edge). Conventional systems thus provide only a restricted sampling that in effect discards $>99 \%$ of the diffraction data. 


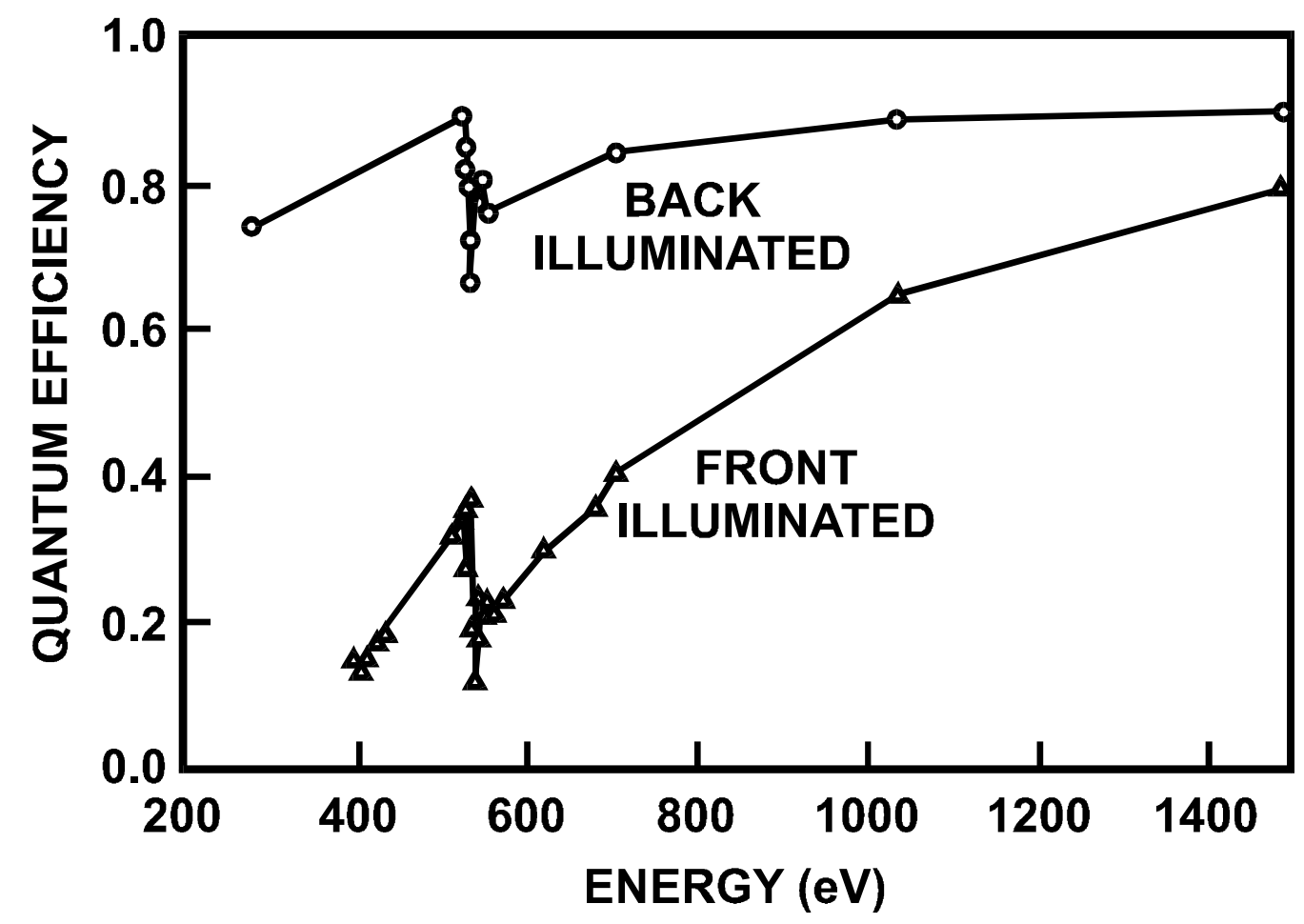

Fig. 3: Comparison of quantum efficiency versus energy for a back-thinned, back-illuminated CCD and for a frontilluminated $\mathrm{CCD}$ that is not of a thin-gate design. ${ }^{2}$ Although the back-illuminated design is more efficient, split events, noise, and poor resolution limit the utility of this type of CCD for light elements $(Z<13)$. The frontilluminated thin-gate design developed at JPL has efficiency closer to that of the back-illuminated design, for energies below $1 \mathrm{KeV}$, without these drawbacks. ${ }^{1}$

\section{CAPABILITIES OF CHEMIN RELEVANT TO PROCESS CONTROL}

Although CHEMIN is not yet commercially available, the existing prototype demonstrates that the instrument has many applications on Earth in process control.

\subsection{Analysis of Minute Samples}

CHEMIN can routinely handle much smaller samples than existing separate X-ray diffraction and X-ray fluorescence systems. This capability is important whenever a small sample has been collected or synthesized. CHEMIN can be useful in detecting rare materials that are difficult to identify and in analyzing synthesized special materials that can only be made in small amounts. CHEMIN can also analyze small amounts of precious or historic materials (e.g., ceramics or paint) for purposes of research, authentication, or restoration.

\subsection{Trace Contaminants}

CHEMIN can be useful in identifying small amounts of contamination. Metallic and organic contaminants can move through groundwater attached to colloids (fine particles). In situations where radionuclide-contaminated colloids occur, correlating nuclides with specific mineral colloids can be very difficult but is crucial for predicting contaminant migration. For example, at the Nevada Test Site, small amounts of plutonium appear to be migrating in the groundwater, possibly attached to natural colloids. $^{3}$ Colloids are difficult to collect, and only very small samples are generally available. Because CHEMIN can analyze less than a milligram of material, CHEMIN has significant capability for this type of analysis. 


\subsection{Analysis in Restricted Spaces}

CHEMIN can be used when a small instrument is required to perform analyses inside a shielded container such as a glove box. If CHEMIN became contaminated, for example, by radioactive chemicals, the decontamination or disposal of CHEMIN would be much easier (and cheaper) than if a conventional laboratory X-ray diffraction or X-ray fluorescence instrument became contaminated.

\subsection{Analysis of Complex Mixtures}

Large masses of pure minerals seldom occur in nature. Instead, minerals generally occur as heterogeneous interlocked mixtures. Most rocks or soils that are considered for mining are made up of such mineral mixtures. By using CHEMIN with modern data analysis methods, mineral abundances in complex mixtures can be quickly quantified. This capability allows CHEMIN to be used, for example, to assay mined material as it is processed.

\section{EXPERIMENTAL RESULTS IN THE APPLICATION OF CHEMIN TO MATERIALS USED IN MINING AND MANUFACTURING}

Because many elements and compounds occur with varied crystal forms that have differing properties (hardness, cleavage, optical properties, heat conductivity, electrical conductivity, etc.), knowledge of the crystalline makeup of a material is often crucial in industrial applications. When an industrial process deals with solids in batches, CHEMIN can monitor inputs and outputs. In the mining industry, it is often critical not only to maximize the desired constituents but also to minimize unwanted or dangerous materials. For example, talc mined for use as baby powder is potentially intergrown with minerals of the asbestos family which can be an inhalation hazard. CHEMIN can be used to analyze spot samples as a company surveys talc deposits for possible production of baby powder. During geologic field surveys, CHEMIN could provide immediate chemical and mineralogical analysis of samples with data linked to location by the Global Positioning System (GPS). Currently, samples must be painstakingly marked to document where they were taken, then sent back to a laboratory for analysis. In the mining industry, CHEMIN could determine mineral abundances on the spot. At later stages of mining, CHEMIN could enable more economical mining by providing a cost-effective means of assaying what is being mined quickly and frequently.

Field applications for the mining industry are only one of the potential uses for CHEMIN. Potential uses in industrial plants and in testing and analysis laboratories are equally viable. CHEMIN has been tested with a large variety of natural and synthetic materials. All of these materials have uses in, or are encountered in, some form of industrial application.

\subsection{Synthetic phases (alumina - $\mathrm{Al}_{2} \mathrm{O}_{3}$; silicon - $\mathrm{Si}$ )}

Alumina is commonly used as a grinding compound because of its exceptional hardness, as a ceramic, and as a catalyst. Purity is particularly important in the latter two applications. For these uses, CHEMIN would be a useful instrument in the manufacturing process.

Silicon is used in semiconductor applications where high purity is critical. Feedstocks for production of semiconductor silicon are varied, but most include mineral forms that are readily quantified with CHEMIN (e.g., silica minerals; see section 3.2.4, below). A novel system for extracting alumina and silicon from coal ash has been proposed. ${ }^{4}$ Here too CHEMIN could be integrated into the coal-ash analysis system to provide feedstock selection and optimization.

\subsection{Natural minerals}

\subsubsection{Feldspars (albite, anorthite)}

Albite and anorthite are feldspars that have a wide variety of applications, ranging from abrasives in cleansers to aluminum production. A novel method of aluminum production is employed in Scandinavia, where abundant hydroelectric power and local abundance of Al-rich feldspar permit extraction of Al from feldspar rather than bauxite. The more anorthite in the feldspar relative to albite, the more Al-rich the feedstock (albite contains $\sim 11 \mathrm{wt} \%$ Al whereas anorthite contains $\sim 19$ wt $\%$ 
$\mathrm{Al})$. CHEMIN could be incorporated in the feedstock selection system to maximize the content of anorthite (Ca, $\mathrm{Al}$ rich feldspar with XRD pattern differing from albite) and hence the Al content of the material supplied for electrolytic smelting, while also quantifying the amounts of unwanted minerals (e.g., biotite). In a different industrial application of the same materials, CHEMIN could be used for the selection of the more Si-rich albite components to produce pure Si for solar cells. ${ }^{5}$

\subsubsection{Carbonate minerals (aragonite, calcite, dolomite)}

Aragonite, calcite, and dolomite are three of the most common carbonate minerals on earth. Siderite is relatively rare. There are many applications for carbonate minerals, but one of the major applications is in the cement industry. The preferred raw feedstocks are a slightly dolomitic limestone and clays such as smectite. These must be supplied in the correct proportions and with the optimum compositions (see discussion of smectite, section 3.2.6, below). Dolomite and calcite proportions can be readily measured with CHEMIN, either at the quarry site, at the crushing plant, or at the feed to the kilns. The cement product can also be sampled as it is produced, with a feedback to the kiln operation designed to minimize the production of unwanted constituents (e.g., periclase and alkali sulfates) in the cement. In the feedstock, detrital minerals such as quartz and feldspar are unwanted. Figure 4 shows a CHEMIN diffraction pattern of an aragonite sample containing minor calcite and quartz, illustrating the sensitivity of CHEMIN to minor mineral contaminants.

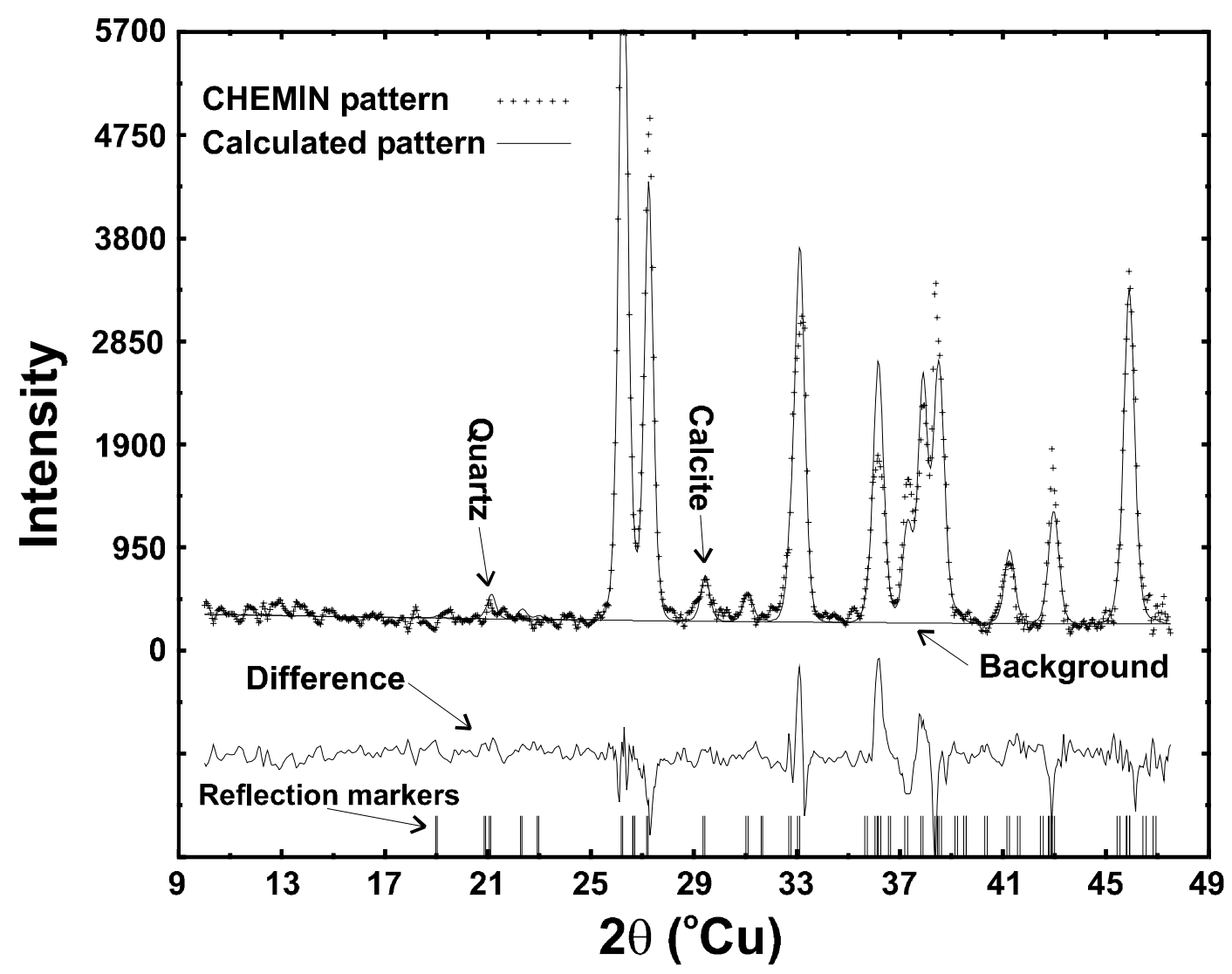

Fig. 4: Rietveld refinement plot of aragonite sample, showing observed CHEMIN data and calculated diffraction pattern. Major diffraction peaks result from aragonite, and minor contributions from quartz $(0.2 \%, \pm 0.2 \%)$ and calcite $(1.6 \%, \pm 1.0 \%)$ can be calculated from the CHEMIN data using the Rietveld method. Difference plot illustrates the difference between the observed CHEMIN data and the calculated pattern. Reflection markers indicate the positions of all aragonite, quartz, and calcite peaks. 


\subsubsection{Salts (halite, löweite, blödite, gypsum, celestine)}

Evaporite salts (e.g., sodium and potassium chlorides, sulfates, and phosphates) have many applications. Current production at evaporation ponds requires monitoring of salt products during the evaporation process. Commercial evaporite salts have applications that range from table salt to fertilizer. At evaporation ponds, the salt products are carefully monitored throughout the evaporation process. CHEMIN can be used to provide both the mineral identification and the determination of key chemical constituents (e.g., K, S) during the evaporation process.

\subsubsection{Silica minerals (cristobalite, quartz, opal)}

There are several crystalline forms of silica with differing properties and uses. Although identical in chemical composition, the different crystalline forms are readily distinguished and quantified by XRD. High-silica sands are important in the glass industry; such sand deposits are typically variable in their content of impurities such as feldspar and Fe-rich minerals that can be readily detected and quantified by CHEMIN. As with the carbonate and clay minerals selected for cement production, CHEMIN could be used either at the quarry site, at the feedstock processing plant, or at the feed to the kilns in order to control the purity of the feedstock.

Crystalline silica is a recognized human carcinogen. CHEMIN can analyze the small amounts of sample that are collected on filters during health and safety assays of airborne silica. Direct analysis of sampling filters is possible, with accurate quantification of any silica polymorphs (particularly quartz, tridymite, and cristobalite) that may be present.

\subsubsection{Iron oxides and hydroxides (magnetite, goethite)}

The iron-oxide mineral magnetite and the iron-hydroxide mineral goethite are both common ores used in steel production. These two minerals occur together where deep weathering profiles superimpose goethite on primary magnetite (as well as other Fe-oxide and silicate minerals). Because smelting properties of these minerals differ, it is important to know the nature of this mixture. CHEMIN can provide the analysis needed. There are several other applications where CHEMIN analyses can be useful in the determination of Fe oxides, ranging from hazards analysis of mine tailings to new methods for production of hexaferrites via goethite and magnetite genesis from steel-pickling liquors. ${ }^{6}$ CHEMIN can be used for the combined chemical and crystal-form analysis that can optimize such production.

\subsubsection{Clays (smectite)}

Smectite is one of the commonest of the clay minerals. It is used in a tremendous variety of applications, from fillers to raw materials for a variety of products. "Clayey limestone" is sometimes mined and used without addition as a feedstock for cement production, but it is necessary to control the relative proportions of minerals obtained from a typically variable rock mass. CHEMIN analyses can provide the information needed for such control (see discussion of carbonate minerals, above). Another example of the necessity of clay composition control is in the use of clays in the brick manufacturing industry. Environmental problems are encountered where the clay feedstock produces high $\mathrm{F}$ emissions from brick kilns. CHEMIN can be used in the clay selection again either at the quarry site, at the crushing plant, or at the feed to the kilns to choose a feedstock that will minimize the cogeneration of $\mathrm{F}$ during brick production.

The importance of clay minerals in environmental studies is difficult to overestimate. Clays are used in drilling systems, as waste-pit liners, and in geoengineering applications. In natural hydrologic systems clays are important as colloid forms that can bind and hold elements that might otherwise adhere to fracture walls. The mineralogy of colloids is important to determine where metallic wastes may or may not move through groundwater when they are attached to colloids. Colloids are difficult to collect from natural waters and only very small amounts of samples are generally available. CHEMIN is ideal for analysis of this type of material.

\subsection{Whole-rock analysis (tuff, dacite, basalt, marble)}

Pure minerals seldom occur in nature. Most rocks or soils that are considered for resource extraction, either on Earth or on other planets, are mineral mixtures. CHEMIN has a proven capability in quantifying the mineral abundances in complex mixtures. ${ }^{1}$ In contrast with many other process-control analytical systems, the combined and simultaneous determination of chemistry and crystal structure type provides a much more accurate determination of chemical and mineralogic abundances in complex mixtures. 


\section{A DETAILED EXAMPLE: PROCESS CONTROL FOR THE PORTLAND CEMENT INDUSTRY USING CHEMIN}

The preceding sections 3.2.2 and 3.2.6 describe the use of CHEMIN in analysis of carbonate minerals and clays, the principal constituents that are mined to produce cement. Cement is produced in a rotary kiln, which continually turns and heats the clay, calcite, and other ingredients used to make cement. Currently, cement manufacturers test for chemical composition with X-ray fluorescence and use that information to make assumptions about the mineral content of their product. However, the XRF method does not directly or accurately determine mineral content. Because the crystalline makeup of the ingredients determines how well the cement performs, cement manufacturers would maintain much better control over their process if they could identify the crystalline constituents of their feedstock. The proportions of minerals in the feedstock can be readily assessed with CHEMIN. Throughout the production process, samples of cement can be analyzed and the results used to minimize the amount of cement product containing unwanted and detrimental constituents.

The combined compositional and mineralogical analysis capabilities of CHEMIN offer great potential for assessing the variability of raw materials and final product in the production of the most commonly used cement, ordinary Portland cement (OPC). OPC consists primarily of a suite of anhydrous calcium-bearing silicates, aluminates, and ferroaluminates formed at high temperature in a rotary kiln. Raw materials for cement typically include limestone $\left(\mathrm{CaCO}_{3}\right)$ as a source for calcium and various other materials (e.g., clays) as a source for silica, alumina, and iron oxide. The final cementitious materials include alite (with the ideal composition $\mathrm{Ca}_{3} \mathrm{SiO}_{5}$ and which accounts for $\sim 50 \mathrm{wt} \%$ of OPC), belite $\left(\beta-\mathrm{Ca}_{2} \mathrm{SiO}_{4} ; \sim 25 \mathrm{wt} \%\right.$ ), tricalcium aluminate $\left(\mathrm{Ca}_{3} \mathrm{Al}_{2} \mathrm{O}_{6} ; \sim 12 \mathrm{wt} \%\right)$, and synthetic brownmillerite $\left(\sim \mathrm{Ca}_{4} \mathrm{Al}_{2} \mathrm{Fe}_{2} \mathrm{O}_{10} ; \sim 8 \mathrm{wt} \%\right)^{7,8,9}$ Each of these phases has different properties (e.g., different hydration rates and reaction products), so their proportions have a profound effect on the properties of a cement. Although these are the primary desired phases in cement, numerous other phases also occur in the system $\mathrm{CaO}-\mathrm{Al}_{2} \mathrm{O}_{3}-\mathrm{Fe}_{2} \mathrm{O}_{3}-\mathrm{SiO}_{2}{ }^{7}$ Hence, the production of a high-quality cement is an art that depends on taking the correct proportion of heterogeneous geological materials through the kiln at the proper rate at the proper temperature. ${ }^{10}$

CHEMIN has the potential to benefit cement production at both the front end and back end of the process. At the front end, CHEMIN could be used to provide information on the variability of the raw materials so that the raw mix can be adjusted prior to introduction into the kiln. This would be particularly important in regions where the raw materials vary significantly in composition within a quarry or when variable waste byproducts from other industries (e.g., flyash) are used as raw materials in OPC production. At the back end, CHEMIN could be used in two ways. First, the use of CHEMIN to analyze clinker (the material exiting a kiln) would provide a real-time evaluation of blending operations and kiln conditions (rotation rate and temperature). Second, the use of CHEMIN to analyze OPC would provide a much greater measure of the product's quality by direct determination of both the composition and phase proportions of the OPC.

Currently, the primary method for evaluating the final OPC product is based solely on compositional analysis. ${ }^{11}$ This approach provides important information on some aspects that affect the quality of cement (e.g., the content of alkali cations), but it fails to provide direct information on the phase content of the cement. Instead, the phase content of the cement is generally inferred using the Bogue method, which is a normative approach for converting a compositional analysis to percentages of phases with ideal compositions. ${ }^{11}$ The deviation of the phase compositions from the ideal can significantly affect the results of the Bogue method. ${ }^{711}$ In addition, the method does not consider the presence of phases other than those desired in OPC (including periclase, alkali sulfates, and non-cementitious polymorphs of the primary cementitious phases). These limitations of the Bogue method have been pointed out as problematic. ${ }^{10}$ In contrast, CHEMIN can provide direct information on both the composition of OPC and on the phase types and abundances.

\section{CONCLUSIONS}

The capability of simultaneously analyzing a sample for both mineralogic and chemical composition, from the same sample portion, opens a wide range of potential applications in process monitoring and control. In particular, systems that rely presently on chemical data to infer mineral or synthetic crystalline forms can be strengthened considerably by the addition of XRD capability. The versatility of this improved approach is such that it can be used directly with virtually any variety of crystalline or mineralogic systems and with most of the major elements of concern to typical mining and industrial processes (although the lighter elements, $\mathrm{C}$ to $\mathrm{Mg}$, will require a thin-gate front-illuminated $\mathrm{CCD}$ design that is not yet available commercially). Advances in this combined mineralogic/chemical analysis method are occurring rapidly and practical application is likely in the near future. 


\section{ACKNOWLEDGMENTS}

This work was supported by the National Aeronautics and Space Administration under the Planetary Instrument Definition and Development Program and by internal program development funds from Los Alamos National Laboratory. This support is gratefully acknowledged.

\section{REFERENCES}

1. D. Vaniman, D. Bish, D. Blake, S. T. Elliott, P. Sarrazin, S. A. Collins, and S. Chipera, "Landed XRD/XRF analysis of prime targets in the search for past or present Martian life," J. Geophys. Res. 103, pp. 31,477-31,489, 1998.

2. B. E. Burke, J. A. Gregory, M. W. Bautz, G. Y. Prigozhin, S. E. Kissel, B. B. Kosicki, A. H. Loomis, and D. J. Young, "Soft-X-ray CCD imagers for AXAF," IEEE Trans. Elect. Dev. 44, pp. 1633-1642, 1997.

3. A. B. Kersting, D. W. Efurd, D. L. Finnegan, D. J. Rokop, D. K. Smith, and J. L. Thompson, "Migration of plutonium in ground water at the Nevada Test Site," Nature 397, pp. 56-59, 1999.

4. V. L. Rayzman, S. A. Shcherban, and R. S. Dworkin, "Technology for chemical-metallurgical coal ash utilization." Energy and Fuels 11, pp. 761-773, 1997.

5. J. R. Stubergh, "Anorthosite resources in Norway and environmental advantages by using the continuous process for production of silicon and aluminum compared with the commercial process," Scandinavian J. Metallurgy 25, pp. 80-86, 1996.

6. J. Dufour, R. Latorre, C. Negro, F. Lopezmateos, E. M. Alcala, and A. Formoso, "Optimal iron-oxides for obtaining hexaferrites," Journal de Physique IV, 7, pp. 87-88, 1997.

7. F. M. Lea, The Chemistry of Cement and Concrete (3rd edition), Chemical Publishing Company, New York, 1971.

8. S. Mindess and J. F. Young, Concrete, Prentice-Hall, New Jersey, 1981.

9. D. E. Macphee and E. E. Lachowski, "Cement components and their phase relations," in Lea's Chemistry of Cement and Concrete, P. C. Hewlett, ed., $4^{\text {th }}$ edition, pp. 95-129, Arnold, London, 1998.

10. F. P. Glasser, "The burning of Portland cement," in Lea's Chemistry of Cement and Concrete, P. C. Hewlett, ed., $4^{\text {th }}$ edition, pp. 195240, Arnold, London, 1998.

11. C. D. Lawrence, "The constitution and specification of Portland cements," in Lea's Chemistry of Cement and Concrete, P. C. Hewlett, ed., $4^{\text {th }}$ edition, pp. 131-193, Arnold, London, 1998. 